\title{
Narrativas sobre saúde e doença: o encontro da ciência com a espiritualidade
}

\author{
Narratives on health and disease: where science meets \\ spirituality
}

Arthur Fernandes da Silva', Ana Carolina Duarte de Oliveira', Marcelo Cruz Oliveira', Sandra Barreto Fernandes da Silva'

'Universidade Federal do Cariri, Barbalha (CE), Brasil.

\section{RESUMO}

O curso de medicina da Universidade Federal do Cariri (UFCA) agrega um currículo com propostas de integração de conhecimentos e habilidades através de metodologia problematizadora desde 2001. A temática de saúde e espiritualidade foi pouco abordada ao longo dos primeiros anos, até o surgimento de um grupo de estudos que promoveu uma monitoria de integração da espiritualidade na disciplina de semiologia médica. Os estudantes da disciplina de semiologia médica foram acompanhados por monitores e professores orientadores em aulas expositivas, simulações realísticas e atividades práticas em hospital, com foco na abordagem da dimensão espiritual do paciente. O conjunto de ações realizados possibilitou, aos monitores e professores orientadores, profundas reflexões em torno da importância do ensino da abordagem da espiritualidade do paciente aos acadêmicos, como estratégia para promoção de conhecimentos integrados, habilidades inovadoras e atitudes direcionadas ao holismo e à compaixão.

PALAVRAS-ChAVE: Educação médica. Espiritualidade. Saúde holística.

Recebido: Dez. 25, 2016 Aceito: Fev. 15, 2017

\section{COMO CITAR ESTE ARTIGO}

Silva AF, Oliveira ACD, Oliveira MC Silva SBF. Narrativas sobre saúde e doença: o encontro da ciência com a espiritualidade. Interdisciplinary. Journal of Health Education. 2016 Ago-Dez;1(2):139-143. http://dx.doi. org/10.4322/ijhe.2016.024

\section{CORRESPONDÊNCIA}

Arthur Fernandes da Silva

Universidade Federal do Cariri

R. Divino Salvador, 284, Centro, CEP 63180-000, Barbalha (CE), Brasil tucafsilva@gmail.com

\section{FONTE DE FINANCIAMENTO}

Pró-Reitoria de Extensão e

Pró-Reitoria de Ensino da

Universidade Federal do Cariri.

\section{CONFLITO DE INTERESSE}

Os autores declararam não

haver conflitos de interesse.

O estudo foi realizado na Universidade Federal do Cariri, Barbalha (CE), Brasil.

Este trabalho foi apresentado no Evento III Mostra da Universidade Federal do Cariri, na categoria pôster eletrônico.

Todos os autores leram e aprovam a versão final submetida ao Interdisciplinary Journal of Health Education (IJHE).

\section{ABSTRACT}

The Medical School of the Universidade Federal de Cariri (UFCA) has added a curriculum proposing the integration of knowledge and skills through a problematizing methodology since 2001. The theme of spirituality and health was little approached during the first years, until the emergence of a group of students which promoted a monitoring program on the integration of spirituality in the discipline of medical semiotics. The students of the discipline of medical semiotics were accompanied by monitors and instructors in lectures, realistic simulations and practical activities in hospital, focusing on patient's spiritual dimension. The set of actions enabled monitors and tutors to reflect deeply on the importance of teaching the patient's spirituality approach to students, as a strategy to promote integrated knowledge, innovative skills and attitudes towards holism and compassion.

KEYWORDS: Medical education. Spirituality. Holistic health. 


\section{Contextualização}

No curso de graduação em medicina os estudantes têm a oportunidade de desenvolver habilidades, competências e atitudes direcionadas ao conhecimento da história clínica do paciente e de sua família, obtendo mais alguns detalhes relacionados através do exame físico do doente. O termo holismo foi criado para significar "[...] a tendência natural de formar complexos que são maiores que a soma das partes através da evolução criativa" ${ }^{\prime 1}$, renovando o princípio de mesma ideia lançado pelo filósofo Aristóteles na Grécia antiga, e contrapondo diretamente o pensamento de Bacon, que no século XVII propôs que princípios derivados de casos mais simples pudessem ser aplicados para construir maiores previsões².

A proposta de atenção à saúde baseada no holismo, isto é, na consideração do indivíduo como um complexo conjunto de especificidades em constante interação com o meio ambiente, surge para enfatizar a necessidade do enfrentamento das questões da saúde de forma ampla, visto que a mesma representa um campo interdisciplinar, cuja complexidade requer conhecimentos de múltiplas áreas, como as questões clínicas, epidemiológicas, comportamentais, sociais, culturais e espirituais ${ }^{3}$.

Espiritualidade pode ser definida de muitas formas, conforme convicções filosóficas, existenciais e espirituais do autor em questão $0^{4-7}$. Alguns autores propõem a inclusão de caracteres psíquicos como paz, harmonia, significado, propósito e satisfação na vida dentro do conceito de espiritualidade. Outros entendem que a espiritualidade está ligada a esses caracteres, mas deve ser vista uma construção a parte, mais ligada ao imaterial e sagrada. Entenderemos aqui, de acordo com Koenig et al. ${ }^{8}: 1$. Espiritualidade como recurso individual e subjetivo de conexão com o transcendente (seja a si mesmo, o outro, Deus ou outra divindade); 2. Religião como sistema organizado de crenças e práticas, que envolve a presença de hierarquias, líderes / sacerdotes e dogmas a serem seguidos; e 3. Religiosidade como a relação ou o exercício individual de cada sujeito com sua religião.

Segundo Saad et al. ${ }^{9}$ (p. 108), diversas pesquisas científicas demonstraram a influência da espiritualidade no tratamento de patologias, não sendo por acaso que $\operatorname{Basmajian}^{10}$ (p. 109) se refere à Medicina Comportamental como a terceira revolução terapêutica, ladeando a farmacologia e a cirurgia. Subsidiando a consolidação da saúde holística anteriormente explanada através da comprovação dos benefícios do desenvolvimento da espiritualidade para o estado de saúde, mais de 850 pesquisas analisaram a interface entre o envolvimento espiritualista e aspectos de saúde mental, tendo a maior parte delas evidenciado que pessoas que desenvolvem práticas religiosas vivenciam melhor a saúde mental e se adaptam mais facilmente ao estresse.

É possível que a melhor justificativa para se abordar as questões espirituais do doente é que grande parte dos pacientes têm crenças religiosas e necessidades espirituais. Pelo menos 96\% dos americanos creem em Deus, mais de 90\% rezam, quase $70 \%$ são membros de igreja e mais de $40 \%$ frequentaram igrejas, sinagogas ou templos nos últimos sete dias ${ }^{11}$.

Três revisões sistemáticas da literatura encontraram mais de três mil estudos experimentais sobre espiritualidade e saúde ${ }^{8,12,13}$. Demonstrou-se que pessoas com maiores níveis de religiosidade / espiritualidade têm menos depressão, tentativas de suicídio, ansiedade e uso de substâncias, bem como vivem com mais qualidade, tendo remissão mais rápida de sintomas depressivos e melhores prognósticos psiquiátricos ${ }^{8}$.

Tendo em vista esse corpo de evidências, é possível entender porque, em sendo a dimensão espiritual inerente a muitas pessoas, negligenciar a abordagem e atenção a essas questões equivale a desconsiderar a situação social ou estado psicológico do indivíduo, promovendo um cuidado distante do "integral' ou "holístico"14.

Estudos e pesquisas sobre a influência da espiritualidade na saúde têm se disseminado há algumas décadas. Nos Estados Unidos, por exemplo, apenas 17 das 126 faculdades de medicina acreditadas ofertavam atividades formais ligadas à 
espiritualidade em 1994; em 1998, a cifra chegava a 39 instituições, e em 2004 já havia atividades nessa linha em 84 faculdades de medicina do país ${ }^{15}$.

No Brasil, a Universidade Federal do Ceará (UFC) é pioneira na implantação de uma atividade similar, através da disciplina optativa Medicina e Espiritualidade no Curso de Medicina da Faculdade de Medicina na cidade de Fortaleza no ano de 2006, sendo seguida pela Universidade Federal do Triângulo Mineiro (Saúde e Espiritualidade) e pela Universidade Federal do Rio Grande do Norte (Medicina, Saúde e Espiritualidade) $)^{16}$.

O curso de medicina da Universidade Federal do Cariri (UFCA) agrega um currículo com propostas de integração de conhecimentos e habilidades através de metodologia problematizadora desde 2001. A temática de saúde e espiritualidade foi pouco abordada ao longo dos primeiros 12 anos, até que em 2012, surgiu um grupo de estudos em espiritualidade e saúde que deu origem, no ano seguinte, à Liga Acadêmica de Saúde e Espiritualidade do Cariri (LIASE), a qual, hoje, é um programa de extensão que mobiliza e difunde trabalhos e práticas dentro de uma visão integral do ser humano no curso, na universidade e na região. A partir da influência da LIASE, e do reconhecimento da necessidade de inserir mais abordagens sobre espiritualidade e saúde no currículo de forma complementar à extensão, foi idealizada a monitoria de integração em ensino e extensão intitulada como Introdução à Espiritualidade em Semiologia Médica.

\section{Descrição da experiência}

O método implementado visou a construção de um raciocínio clínico baseado em etapas (etapa 1: conhecimentos; etapa 2: habilidades; etapa 3: atitudes), seguindo-se uma reflexão em roda de conversa ao final das atividades, conforme a Figura 1.

As atividades foram iniciadas com discussões teóricas em aulas expositivas e com apoio de casos clínicos elaborados pelos professores orientadores em conjunto com os monitores - etapa 1: conhecimentos. Seguiu-se com simulação realística - etapa 2: habilidades - em duas modalidades: na primeira, os estudantes foram divididos em duplas e orientados a realizar a entrevista espiritual entre si; na segunda, dois monitores representaram pacientes com contextos clínicos diferentes, e os estudantes foram solicitados a realizar as entrevistas espirituais nessas situações. Em continuidade, foram realizadas as atividades práticas - etapa 3: atitudes - com pacientes internados no Hospital Maternidade São Vicente de Paulo. Os monitores, com apoio de enfermeiros e psicólogos do hospital, selecionaram os pacientes com

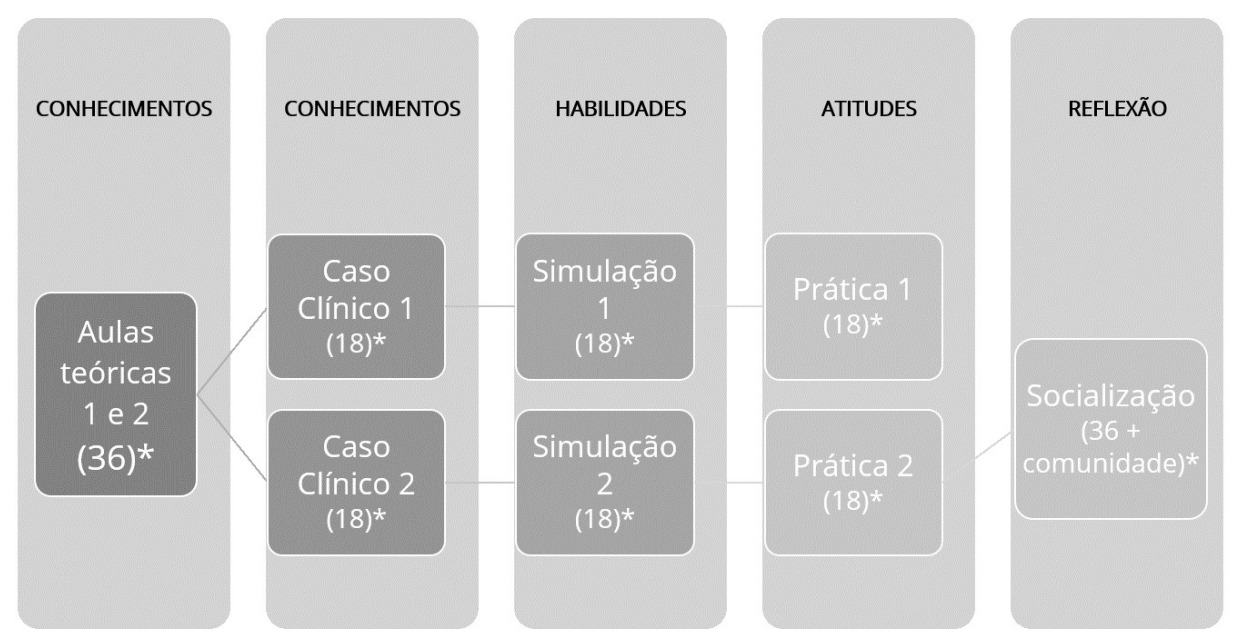

Figura 1. Conteúdo programático da monitoria. *número de estudantes participantes por ação. Fonte: Elaborado pelos autores (2016). 
melhores condições (entenda-se: situação clínica, contexto emocional) para colaborar com a atividade e os apresentaram aos estudantes, os quais foram orientados a coletar a história espiritual e, em seguida, discutiram todos os casos individualmente com todo o grupo, evidenciando as causas dos sofrimentos espirituais identificados e as possibilidades de intervenção do profissional de saúde.

\section{Resultados e impactos}

O conjunto de ações realizados possibilitou, aos monitores e professores orientadores, profundas reflexões em torno da importância do ensino da abordagem da espiritualidade do paciente aos acadêmicos, como estratégia para promoção de conhecimentos integrados, habilidades inovadoras e atitudes direcionadas ao holismo e à compaixão. A socialização de experiências, reunindo a equipe gestora do projeto, os estudantes abordados e membros do hospital que serviu como campo de práticas, permitiu ao grupo vislumbrar o impacto positivo que a assistência à dimensão espiritual do ser humano pode trazer para a saúde do paciente, o qual expressa tal desejo ${ }^{17}$. Não obstante, permitiu reconhecer o ganho individual e coletivo do treinamento direcionado para a abordagem da espiritualidade humana, cuja falta, juntamente com a falta de tempo, é uma das maiores barreiras apontadas para justificar a falta de discussões nessa temática ${ }^{18}$.

\section{Considerações finais}

A disciplina de Semiologia no curso de Medicina abre as portas da compreensão do estudante para a complexidade do paciente como todo. Portanto, deve integrar os aspectos físicos e também componentes emocional, social e espiritual da pessoa, para que se construa uma história e abordagem integrais, compreendendo-a como uma unidade holística. Uma das principais estratégias para a promoção de cuidado integral é incentivar o estudo e o treinamento na abordagem da dimensão espiritual do ser humano, levando em consideração os aspectos espirituais do paciente e do próprio estudante e/ou profissional. Reconhecendo a influência positiva da espiritualidade na manutenção e na promoção da saúde, é importante que novos estudos discriminem os melhores métodos e ferramentas para o ensino em saúde e para a abordagem junto ao paciente.

\section{Referências}

1. Smuts JC. Holism and evolution. Londres: Kessinger Publishing; 1926.

2. Glass DJ, Hall N. A brief history of the hypothesis. Cell. 2008;134(3):378-81. PMid:18692458.

3. Garcia MAA, Pinto ATBCS, Odoni APC, et al. Interdisciplinaridade necessária à educação médica. Rev Bras Educ Med. 2007;31(2):147-55. http://dx.doi.org/10.1590/S0100-55022007000200005.

4. Koenig HG. Concerns about measuring "spirituality” in research. J Nerv Ment Dis. 2008;196(5):349-55. PMid:18477877. http://dx.doi.org/10.1097/NMD.0b013e31816ff796.

5. Puchalski CM. Spirituality and end-of-life care: a time for listening and caring. J Palliat Med. 2002;5(2):289-94. PMid:12006231. http://dx.doi.org/10.1089/109662102753641287.

6. Lucchetti G, Lucchetti AL, Vallada H. Measuring spirituality and religiosity in clinical research: a systematic review of instruments available in the Portuguese language. Sao Paulo Med J. 2013;131(2):112-22. PMid:23657514. http://dx.doi. org/10.1590/S1516-31802013000100022.

7. King MB, Koenig HG. Conceptualising spirituality for medical research and health service provision. BMC Health Serv Res. 2009;9(1):116. PMid:19594903. http://dx.doi.org/10.1186/1472-6963-9-116.

8. Koenig HG, McCullough ME, Larson, DB. Handbook of religion and health. New York: Oxford University Press; 2001.

9. Saad M, Masiero D, Battistella LR. Espiritualidade baseada em evidências. Acta Fisiátrica. 2001;8(3):107-12.

10. Basmajian JV. The third therapeutic revolution: behavioral medicine. Appl Psychophysiol Biofeedback. 1999;24(2):107-16. PMid:10575538. http://dx.doi.org/10.1023/A:1022222327161. 


\section{ijhe}

11. Bonelli RM, Koenig HG. Mental disorders, religion and spirituality 1990 to 2010: a systematic evidence-based review. J Relig Health. 2013;52(2):657-73. PMid:23420279. http://dx.doi.org/10.1007/s10943-013-9691-4.

12. Koenig H, King D, Carson VB. Handbook of religion and health. 2nd ed. New York: Oxford University Press; 2012.

13. Lutgendorf SK, Russell D, Ullrich P, Harris TB, Wallace R. Religious participation, interleukin-6, and mortality in older adults. Health Psychol. 2004;23(5):465-75. PMid:15367066. http://dx.doi.org/10.1037/0278-6133.23.5.465.

14. Institute of Medicine. Approaching death: improving care at the end of life. Washington: National Academy Press; 1997.

15. Fortin AH 6th, Barnett KG. Medical school curricula in spirituality and medicine. JAMA. 2004;291(23):2883. PMid:15199044. http://dx.doi.org/10.1001/jama.291.23.2883.

16. Righetti S, Felippe C. Pode a fé curar? Campinas: SBPC; 2005 [citado em 2013 Set 1]. Disponível em: http://www.comciencia. br/reportagens/2005/05/06_impr.shtml

17. Best M, Butow P, Olver I. Do patients want doctors to talk about spirituality? A systematic literature review. Patient Educ Couns. 2015;98(11):1320-8. PMid:26032908.

18. Best $M$, Butow $P$, Olver I. Doctors discussing religion and spirituality: a systematic literature review. Palliat Med. 2015;30(4):327-37. PMid:26269325.

\section{Contribuição dos autores}

Arthur Fernandes da Silva contribuiu com a concepção, análise e interpretação dos dados, com a redação do artigo e revisão crítica relevante do conteúdo intelectual, com a aprovação final da versão a ser publicada e com a garantia da exatidão e integridade de todos os aspectos do trabalho em qualquer parte da obra. Ana Carolina Duarte de Oliveira contribuiu com a concepção, análise e interpretação dos dados, com a redação do artigo e revisão crítica relevante do conteúdo intelectual, com a aprovação final da versão a ser publicada e com a garantia da exatidão e integridade de todos os aspectos do trabalho em qualquer parte da obra. Marcelo Cruz Oliveira contribuiu com a concepção do trabalho e com a aprovação final da versão a ser publicada e com a garantia da exatidão e integridade de todos os aspectos do trabalho em qualquer parte da obra. Sandra Barreto Fernandes da Silva contribuiu com a concepção, análise e interpretação dos dados, com a redação do artigo e revisão crítica relevante do conteúdo intelectual, com a aprovação final da versão a ser publicada e com a garantia da exatidão e integridade de todos os aspectos do trabalho em qualquer parte da obra. 